\title{
Industrial Emergency Response Training: An Assessment of Long-Term Impact of a Union-Based Program
}

\author{
Jennifer A. Fernandez, ms, ${ }^{*}$ Judith A. Daltuva, msw, mA, and \\ Thomas G. Robins, MD, MPH
}

\begin{abstract}
Background The long-term impact of the United Automobile Workers' (UAW) Industrial Emergency Response Training on health and safety conditions and practices in plants is described. Two strategies are combined in this 24-hour training: the use of peer (worker) trainers and a participant-centered approach, the Small Group Activity Method (SGAM). Methods Impact was assessed through a telephone survey of 67 trainees conducted on average 16.8 months post-training.

Results $74 \%$ of trainees reported using at least one of the provided written training materials after training. Of those reporting an accident in their facility after training, $88 \%$ said it was handled differently because of training. Trainees report that peertrainers are more knowledgeable and communicate better than do other types of trainers. Trainees also reported that SGAM made training more applicable to their workplace. 98.5\% of trainees like the methods utilized.

Conclusions Worker-trainers and SGAM are effective training methods enhancing the long-term impact of union-based workplace health and safety training programs. Am. J. Ind. Med. 38:598-605, 2000. ๑ 2000 Wiley-Liss, Inc.
\end{abstract}

KEY WORDS: small group activity method; worker-trainers; peer-trainers; industrial emergency response; training; union

\section{INTRODUCTION}

In 1990, the International Union of the United Automobile, Agricultural Implement, and Aerospace Workers (UAW) was awarded a grant from the National Institute of Environmental Health Sciences (NIEHS) to provide training related to the Occupational Safety and Health

Department of Environmental Health Sciences, School of Public Health, University of Michigan, Ann Arbor, Michigan

Contract grant sponsor: NIEHS; Contract grant number: NIH 2U45-ES06180-04

*Correspondence to: J. Fernandez, M6168 SPH II, 109 Observatory Rd., Ann Arbor, MI 48109-2029. E-mail: jafernan@umich.edu

Accepted 17 May 2000
(OSHA) standard 1910.120 ("HAZWOPER"). As a part of this grant, the UAW provides 24-hour Industrial Emergency Response (IER) training to its members.

The UAW seeks to educate trainees about their role in dealing with chemical emergencies, the harmful effects of some of the chemicals with which they work, where to find additional information about the effects of chemicals, and preventative strategies to reduce hazards. The aim of the program is to train the trainees as First Responders at the Operations Level.

Initially, the UAW IER training was conducted by staff from the International Health and Safety Department using a conventional lecture methodology. The UAW's program has evolved in two critical respects since 1996: (1) peer (worker) trainers have been used exclusively as instructors and (2) a participant-centered educational method, called the Small Group Activity Method (SGAM), has been utilized to conduct the IER training programs. 
Worker-trainers were first incorporated into the program in 1991 and have assumed increasing control over training sessions. These worker-trainers are granted release time to carry out their training responsibilities while continuing their full-time jobs at their respective plants. The use of worker-trainers, as compared to consultants, representatives from management, or even the UAW Health and Safety Department staff, is expected to increase the degree to which trainees will share similar experiences and beliefs about their work, and will identify with the trainers.

SGAM was developed in the 1970s by the British Trade Union Congress for use in health and safety training. Training is organized around small groups of workers investigating and solving problems presented in case studies.

Most of the previous studies of training programs using worker-trainers and SGAM or other similar participantcentered methods [Luskin et al., 1992; McQuiston et al., 1994; Merrill,1994] carried out evaluation activities within several months of completion of the training programs. However, longer term follow-up appears critical in assessing the effectiveness of health and safety training programs which have as a goal organizational change in handling health and safety. The current article focuses on trainee evaluations of the impact of the UAW IER Training Program based on interviews conducted on average $1 \frac{1}{2}$ years after training. A combination of quantitative and qualitative evaluation methodologies were used to investigate training impact, trainee actions and workplace conditions.

\section{METHODS}

A survey instrument was developed for phone interviewer administration to IER trainees jointly by UM evaluation team members, UAW Health and Safety staff, and four worker-trainers from the IER program. Workertrainers participated both in identifying key areas the survey should cover and in the construction of questions. Conceptual categories of developed questions include sharing and using course materials, health and safety involvement since the training, frequency and handling of accidents and incidents, improvements in health and safety, union-management communication, and trainees' perceptions of the effectiveness of the use of worker-trainers and the Small Group Activity Method. Qualitative open-ended responses were frequently solicited after close-ended questions to assist in the elaboration and interpretation of quantitative data. (The questionnaire is available upon request from the authors.)

Eight 24-hour IER training programs were conducted under the auspices of the grant between December 1996 and October 1997. Twelve trainees were selected to pilot-test the interview instrument, five from an immediately prior program not part of this study and seven randomly chosen from the first program. Both the pilot test and subsequent interviews were conducted using the same methods. First, a cover letter explaining the purpose of the study, together with a copy of the questionnaire, was mailed to the trainees at the home address listed on their training session registration forms. Approximately 2 weeks after the mailing, prospective participants were phoned to complete the 20-minute interview at that time or to arrange a later phone interview appointment. Both UAW worker-trainers and UM staff were to share in the conduct of phone interviews. In practice, all structured telephone interviews were conducted by the UM evaluators. If a trainee could not be reached after 15 attempts calling at various times of day on weekdays and weekends, he or she was classified as lostto-follow-up.

Interview data were coded, double entered into SPSS for Windows statistical software (SPSS Inc., Chicago, IL), and cleaned by checking logic sequences and ranges for individual questions. Frequencies and descriptive statistics were generated for each quantitative variable. Bivariate Pearson correlation coefficients were also computed. Two experienced researchers independently constructed categories for qualitative responses on the basis of themes, concepts, or similar features. The two researchers then compared both conceptual categories and assignments of individual responses to these categories and consensually derived a simple coherent classification scheme.

\section{RESULTS}

One hundred and sixty-two trainees attended the target training; of these seven were used to pre-test the survey instrument and 27 had disconnected telephones or had moved with no forwarding address. Of the remaining 128 trainees, $68(53 \%)$ were successfully contacted by telephone and available to be interviewed. Of these, 67 (98.5\%) completed the interview. On average, interviews were conducted 16.8 months after training (range: 3.8-21.8 months).

Table I presents the study demographics of those successfully interviewed. The cohort consisted predominately of white union males with an average age of 39.8 years and average seniority of 11.4 years. Twenty-eight percent of union members held a union health and safety position. Over $74 \%$ of trainees reported that they shared at least one of the training materials provided at the training with co-workers. As can be seen in Figure 1, the majority of the materials were used by over $50 \%$ of the trainees. Materials were used in a variety of ways. A representative statement concerning use of these materials:

I used the NIOSH guide to enlighten labor and management about hazardous chemicals and what chronic exposure can do to them. The 
TABLE I. Demographics of Evaluation Participants and Non-participants who Attended a UAW 24-hour Industrial Emergency Response Training Program Between October 1996 and May 1997

\begin{tabular}{lccc} 
& $\begin{array}{c}\text { Participants* } \\
\text { (n= 67) }\end{array}$ & $\begin{array}{c}\text { Contactable } \\
\text { non-participants } \\
\text { (n=61) }\end{array}$ & $\begin{array}{c}\text { Non-contactable** } \\
\text { non-participants } \\
\text { (n= 27) }\end{array}$ \\
\hline \% Male & 83.6 & 85.2 & 92.0 \\
Race: & & & \\
$\quad$ White & 85.9 & 89.7 & 76.9 \\
$\quad$ African American & 7.8 & 8.6 & 19.2 \\
Hispanic & 1.6 & 0 & 3.8 \\
Native American & 1.6 & 1.7 & 0 \\
Other & 3.1 & 0 & 0 \\
Position: & & & \\
Union & 78.8 & 72.1 & 53.8 \\
$\quad$ Skilled trades & $36.5^{\mathrm{a}}$ & $39.0^{\mathrm{a}}$ & $21.4^{\mathrm{a}}$ \\
$\quad$ Holding H\& Soffice & $28.8^{\mathrm{a}}$ & $21.4^{\mathrm{a}}$ & $28.6^{\mathrm{a}}$ \\
$\quad$ Holding appointed office & $65.4^{\mathrm{a}}$ & $46.5^{\mathrm{a}}$ & $50.0^{\mathrm{a}}$ \\
Salaried & 21.2 & 27.9 & 46.2 \\
Mean Age \pm SD (yrs.) & $39.8 \pm 9.3$ & $41.6 \pm 8.9$ & $38.8 \pm 8.3$ \\
Mean Seniority \pm SD (yrs.) & $11.4 \pm 8.2$ & $12.8 \pm 8.7$ & $8.8 \pm 8.9$ \\
\hline
\end{tabular}

*Participant $=$ trainee who completed the phone interview.

** Had disconnected phone or had moved with no forwarding address.

apercent of all those holding a union position.

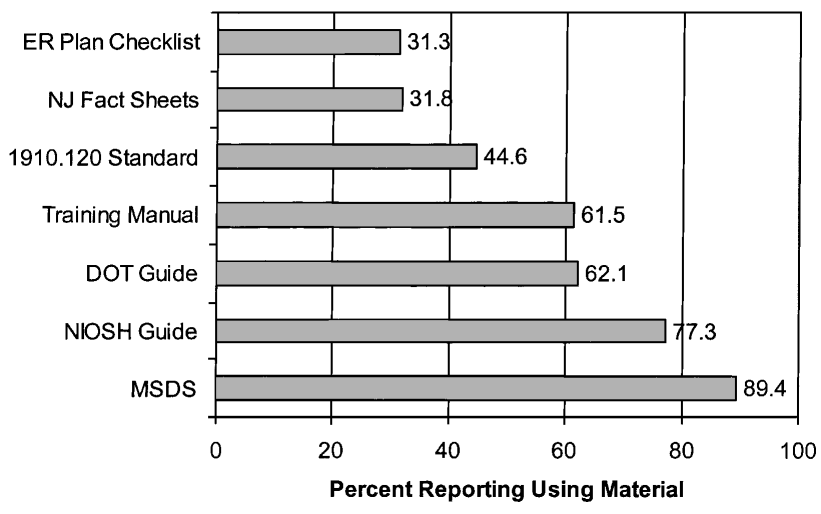

FIGURE 1. The percent of trainees attending a UAW 24-hour Industrial Emergency Response Training Program, October 1996 to May 1997, who reported during a telephone survey their continuing use of training material post training.

DOT guide to see when we did have an acid spill to see what it suggested about how to contain the spill and what PPE to use...I used them in reference to get information to give to other workers.

Of those interviewed, $42.4 \%$ reported that an incident or accident similar to those discussed during the training had occurred at their workplace since the training. Most of these involved chemical spills or fires. Among those reporting such an incident, $88.5 \%$ said that it was handled differently because of the UAW IER training. Trainees reported better handling of emergency situations due to increased knowledge, awareness, or concern. One trainee stated that during an incident in his plant that, "everybody knew what to do and what it was." Another trainee stated specifically that they [the trainees], "know more of procedures, got MSDS out, roped off area according to wind direction." The following trainee's statement highlights how the training impacted company procedures:

We're more aware of the chemicals we use. The safety committee implemented no new chemicals in the plant unless they are approved by the safety committee.

Over $50 \%$ of trainees reported a belief that incidents had been avoided as a result of the training. Trainees stated that accidents were avoided as a result of increased awareness and concern.

Over $62 \%$ of trainees reported improved management communication since the training. Several trainees observed that the training opens a dialogue and improves commu- 
nication between union and management. A union trainee stated,

because...the training team was half supervision and half employees [that] now when we go to supervisors they were there and know we aren't blowing smoke. They tend to listen.

Even when approaching someone who did not attend, trainees see the benefits of the training.

When you can back up what you say people listen to you. Before it was ignored. Pulling out documentation from training gives you proof for statements that are made.

As shown in Figure 2, more than half of the trainees reported improvements were needed in each of eight areas queried. As shown in Figure 3, for seven of the eight areas, more than $50 \%$ of the trainees reported improvements were completed when they were needed.

Table II shows trainees' assessments of worker-trainers. Most trainees (59.7\%) reported worker-trainers communicate better than other types of trainers. They "spoke at the right level, not too complicated and didn't talk down to you." Trainees also agreed that worker-trainers are more knowledgeable about trainees' work sites.

They're in the workplace so they know what's going on. They have more knowledge than a consultant of what's going on in the workplace.

Nearly $90 \%$ of trainees reported that classes were more applicable because worker-trainers share their experiences and backgrounds with the trainees and over $75 \%$ stated that they identify more with worker-trainers than other types of

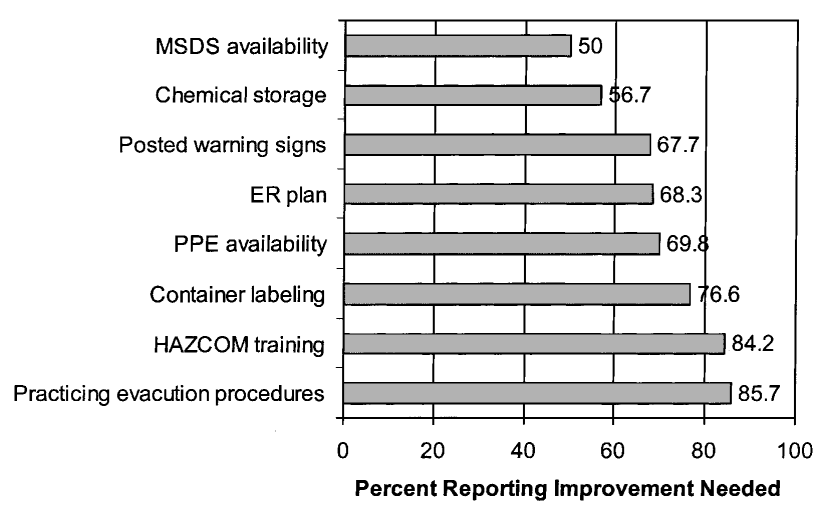

FIGURE 2. The percent of trainees attending a UAW 24-hour Industrial Emergency Response Training Program, October 1996 to May 1997, who reported improvements were needed in the listed health and safety areas.

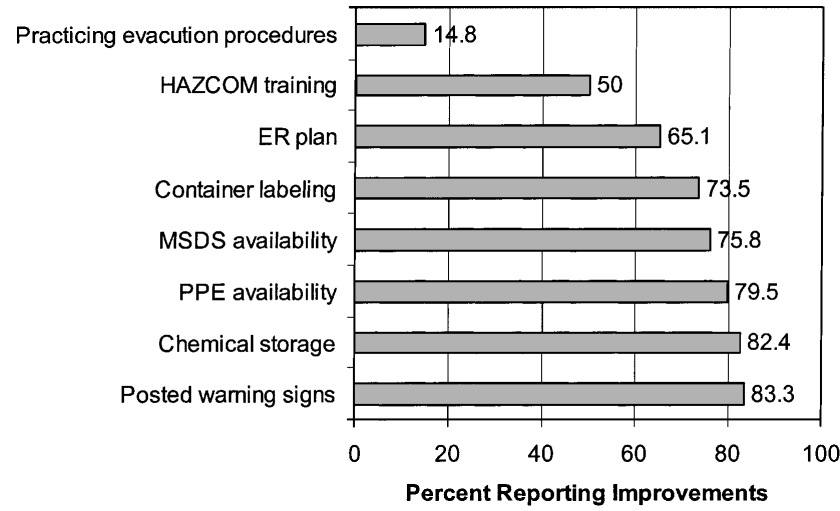

FIGURE 3. The percent of trainees attending a UAW 24-hour Industrial Emergency Response Training Program, October 1996 to May 1997, who reported improvements were completed in the listed health and safety areas when initially reported as needed.

trainers. They can "relate to workers because they are workers." Trainees stated they feel more comfortable with a worker-trainer.

It just seems to be when you have workertrainers it's more relaxed, you're on the same wavelength. You're not afraid to discuss problems with other workers. When it's a consultant you tend to be quiet about things.

Most trainees $(82.1 \%)$ reported that worker-trainers provide motivation to be involved in health and safety. "They motivate me because they've been there."

As shown in Table III, most trainees $(86.5 \%)$ reported that participating in the small task groups, and almost all (95.4\%) reported hearing and sharing personal experiences with other trainees made training more applicable to their working conditions. Very few trainees $(12.1 \%)$ felt that the small task group made learning difficult. The small group activity method was also reported to make the group feel more comfortable and facilitate discussion.

In a small group, [it] gives you a chance to say something. I'm the kind that hushes up in a big group. Once I get to know the people in the small group I open up more.

Almost $60 \%$ of trainees reported having had past training provided by a consultant or professional hired by their company, more than $50 \%$ had past training from a representative from their company's management, $32.8 \%$ from a representative from their company's human resources department, over $37 \%$ from UAW Health and Safety staff, and more than $22 \%$ from some other type of trainer. Only $9 \%$ of trainees reported having received no previous training. 
TABLE II. Responses of Trainees who Attended a UAW 24-hour Industrial Emergency Response Training Program, October 1996 to May 1997, to Statements Concerning Worker-Trainers

\begin{tabular}{|c|c|c|c|c|c|}
\hline & $\begin{array}{c}\text { Strongly } \\
\text { agree }\end{array}$ & Agree & $\begin{array}{l}\text { Neither agree } \\
\text { nor disagree }\end{array}$ & Disagree & Strongly disagree \\
\hline $\begin{array}{l}\text { Other types of trainers } \\
\text { communicate better than } \\
\text { worker-trainers }\end{array}$ & 4.5 & 7.5 & 28.4 & 40.3 & 19.4 \\
\hline $\begin{array}{l}\text { I identified more with the } \\
\text { worker-trainer than I } \\
\text { would have with other } \\
\text { types of trainers }\end{array}$ & 29.9 & 46.3 & 13.4 & 10.4 & 0 \\
\hline $\begin{array}{l}\text { Other types of trainers } \\
\text { provide a more applicable } \\
\text { training class than do } \\
\text { worker-trainers }\end{array}$ & 4.5 & 7.6 & 27.3 & 47.0 & 13.6 \\
\hline $\begin{array}{l}\text { Because worker-trainers } \\
\text { shared their experiences } \\
\text { and backgrounds, the } \\
\text { training was more } \\
\text { applicable to my work site }\end{array}$ & 25.4 & 64.2 & 3.0 & 6.0 & 1.5 \\
\hline $\begin{array}{l}\text { Worker-trainers know } \\
\text { more about my work site } \\
\text { than other types of } \\
\text { trainers }\end{array}$ & 22.4 & 40.3 & 23.9 & 11.9 & 1.5 \\
\hline $\begin{array}{l}\text { Worker-trainers provide } \\
\text { motivation for me to be } \\
\text { more involved with health } \\
\text { and safety }\end{array}$ & 29.9 & 52.2 & 11.9 & 6.0 & 0 \\
\hline
\end{tabular}

When asked if they liked the methods used in the IER training overall, $98.5 \%$ responded positively. Only 9\% reported attending a training that used a method they liked better. Over $68 \%$ reported being more involved in health and safety since the training.

Correlations were examined between key demographic variables such as gender, age, race, seniority, union vs. salaried status, and the outcome variables described above. While some correlations were statistically significant at $\alpha=0.05$ in no case did the absolute value of the correlation coefficient exceed 0.5 , indicating that demographics have only a modest explanatory power for the results presented. Trainee status (union vs. salaried) was never significantly correlated with the outcome variables of interest. There were no significant correlations between the history of attending other types of training and the responses trainees gave about worker-trainers and the small group activity method.
Correlations significant at the $0.4-0.5$ level included: trainees holding a health and safety office were more likely to use New Jersey Fact Sheets $(r=0.49)$; older trainees were more likely to use the DOT guide $(r=0.46)$ while trainees with more seniority were more likely to use the NIOSH guide $(r=0.44)$.

Workers with more seniority were also more likely to report that needed improvements in posting of signs in the workplace had not been completed $(r=0.42)$. However, this same group of workers was more likely to report that chemical storage at their site was adequate $(r=0.49)$ and that improvements were not needed in chemical storage $(r=0.50)$.

\section{DISCUSSION}

As shown by both the quantitative and qualitative responses to this phone survey administered on average 16.8 
TABLE III. Responses of Trainees who Attended a UAW 24-hour Industrial Emergency Response Training Program, October 1996 to May 1997, to Statements Concerning the Small Group Activity Method

\begin{tabular}{lccccc} 
& $\begin{array}{c}\text { Strongly } \\
\text { agree }\end{array}$ & Agree & $\begin{array}{c}\text { Neither agree } \\
\text { nor disagree }\end{array}$ & Disagree & Strongly disagree \\
\hline $\begin{array}{l}\text { My participation in the } \\
\text { small task group made } \\
\text { training more applicable to } \\
\text { my working conditions }\end{array}$ & 31.3 & 55.2 & 10.4 & 3.0 & 0 \\
$\begin{array}{l}\text { Hearing and sharing } \\
\text { personal experiences made } \\
\text { training more applicable to } \\
\text { my working conditions }\end{array}$ & 42.4 & 53.0 & 3.0 & 1.5 & 0 \\
$\begin{array}{l}\text { Participation in the small } \\
\text { task group made learning } \\
\text { difficult for me }\end{array}$ & & & & \\
$\begin{array}{l}\text { Participating in the small } \\
\text { task group encouraged me to } \\
\text { be more involved in health } \\
\text { and safety at my work site }\end{array}$ & 0 & 3.0 & 9.1 & & \\
\hline
\end{tabular}

months post training, trainees regarded the UAW IER training as highly effective and believed that it affected how emergency situations were handled at the work site. In addition to the positive overall assessment, two key elements of the training design, the use of worker-trainers and the Small Group Activity Method, were seen by trainees as particular strengths of the program.

The overall response rate to the survey, 68 of 128 eligible, was modest. Among the 60 non-respondents, 22 were originally assigned to three worker-trainers to complete. Worker-trainers did not complete any of these interviews, apparently due to having to make calls on their own time in addition to their familial and social responsibilities and the effort required to contact trainees working on various shifts. By the time it became clear that this approach was not working, too many months had passed since the training and the interviews were outside the target time frame of the study. However, it appears unlikely that there was significant selection bias in that, among those successfully contacted by phone, $98.5 \%$ agreed to complete the interview. Moreover, even if all the trainees that were not contacted were to have responded negatively, the findings of the study still argue that the program had a significant positive impact on health and safety.

It was important that this evaluation went beyond immediate impressions of training to instead assess training impact after trainees have had many months to reflect on the usefulness. Long-term follow-up allows a reasonable period of time to pass to allow diffusion of new learning, changes in organization culture, implementation of health and safety changes, and the ability to discern their effectiveness. Therefore, it is less likely that the positive responses can be explained by "post-training glow," i.e., the Hawthorne Effect. There was also an abundance of evidence given of the direct effects of the training that could be expected to concretely reduce the risk for illness and injury.

One such direct effect of the training is the continued use of reference materials post training. Among the goals of the training program was the aim to provide the skills and tools needed to use these materials. Other training programs using worker-trainers and SGAM or other participantcentered methods have found similar high percentages of trainees reporting the use of provided materials post training. Merrill [1994] evaluated the Oil, Chemical and Atomic Workers (OCAW) training program where $95 \%$ of trainees used the manual after the training. McQuiston et al. [1994] evaluated the International Chemical Workers Union (ICWU) program which also used a worker-centered participatory empowerment approach. Eighty-five percent of the ICWU trainees continued to use the NIOSH guide, compared to over $77 \%$ of the UAW trainees in the current study (Fig. 1).

Also, $61.3 \%$ of their union trainees used the DOT guide as did $62 \%$ of our trainees. Trainees who completed a course at the New Jersey/New York Hazardous Materials Worker Training Center referred to their manual $51 \%$ of the time as "very valuable" [Weidner et al., 1998]. Among trainees in the current UAW project, $61.5 \%$ referenced their manual after training, as did over $75 \%$ of the union trainees from the ICWU center [McQuiston et al., 1994]. Similarly, 77\% of 
the trainees that attended the New England Consortium's participatory training program referenced their material [Luskin et al., 1992]. These high percentages indicate that participatory methods, such as SGAM, are highly successful at cultivating the skills needed to utilize these materials long term.

This participatory, non-lecture approach to training reflected in SGAM, "is based on the proposition not only that people learn best in small groups, but also that workers naturally function in them in the workplace - that small groups in other words, are the best building blocks of effective organizations" [Merrill, 1994]. The basic premise of SGAM is that it increases worker confidence and makes it evident to workers that they can work collectively to solve problems, leading to greater control over their work environments. Nearly $70 \%$ of UAW trainees reported that they are more involved in health and safety since the training. The OCAW had reported similar findings, with $92 \%$ of trainees reporting a more active union and $86 \%$ reporting that they had made a health and safety complaint or had reported a hazard [Merrill, 1994]. The ICWU evaluation reported $96.9 \%$ of their union attendees attempted to obtain improvements in one or more health and safety-related areas. Over $97 \%$ succeeded in promoting change in one or more categories related to organizational change [McQuiston et al., 1994]. In the current study, for six of eight health and safety areas which the survey inquired, over $60 \%$ of those who believed improvement was needed in a specific area reported improvement (Fig. 3). These high reported success rates strongly suggest that trainees feel confident enough in their knowledge after training to attempt and succeed in changing aspects of their workplace they believe to be hazardous.

A second very important area where organizational change was evident in this evaluation was in the handling of incidents that had occurred in the workplace after training. Of the trainees that reported an incident, $88.5 \%$ noted that an incident was handled differently in a positive way because of the training. The ICWU reported $57.6 \%$ of union trainees and $61.5 \%$ of management trainees reported better handling of incidents [McQuiston, 1994]. Over 50\% of the trainees in the current study also reported that incidents had been avoided as a result of the training. The New England Consortium reported similar results (47\%) [Luskin et al., 1992]. Here again is strong evidence that participantcentered training methods such as SGAM, encourage trainees to become advocates of a safer and healthier work environment. It appears they help promote worker abilities to solve problems and concretely improve health and safety conditions in their workplace. A "culture of safety," as termed by the OCAW, is created where safe work practices are reinforced and everyone is encouraged to be knowledgeable and committed to a safe work environment [Merrill, 1994].
One very important area where this change in organizational culture is tangible is the increase in management communication: $62.5 \%$ of trainees reported better communication. The OCAW saw a similar response: $77 \%$ of trainees reported a more responsive management [Merrill, 1994]. Anecdotal evidence suggests that this communication occurs because in many cases both union and management attend the IER training programs together. SGAM promotes working together during the training. They now possess and can speak the same technical language and have worked together before to solve these types of problems. This cooperation between union and management also helps explain the high success rates mentioned previously in accomplishing improvements in health and safety-related areas.

Although the use of the SGAM is significant in promoting workplace change after training, the positive results seen here also appear related to utilizing workertrainers to deliver the training. Weidner and Luskin have found, "instructor performance to be among the most predictive indicators of self-reported impact at the workplace" [Weidner et al., 1998]. Weidner and Luskin both state that the instructor must be interactive and be able to determine what trainees require in each course given their work conditions, i.e., he or she must be sensitive to the needs of the trainees and committed to worker education. It is clear from the data and anecdotal evidence in this evaluation that trainees perceive worker-trainers as knowledgeable and motivating. The worker-trainers can identify and be sensitive to the needs of the trainees because they are like the trainees. They share the same background and experiences. They possess similar interests and beliefs. Kurtz et al. [1997] reported the results of questionnaires administered to 426 workers who received health and safety training though this same UAW program at a time of transition from the exclusive use of professional Health and Safety Department staff trainers toward peer-trainers. As compared to those trained by professional trainers, trainees who received training from peer-trainers identified more closely with their instructors, had greater belief in their ability to successfully carry out recommended actions, and were more likely to change behaviors as a result of training.

In summary, trainees in this and other similar programs report that both the use of worker-trainers and the Small Group Activity Method are well-received and effective training approaches. Even more convincing is the evidence of organizational change that was reported post training. Trainees became more involved in health and safety, achieved improvements in health and safety areas, contributed to improved incident handling, and to increasing positive communication between management and union employees. These reported direct effects of training are expected to reduce the risk for illness and injury. As seen in other similar programs, these results lead to the conclusion 
that the combination of worker-trainers and the Small Group Activity Method provide an effective strategy for the delivery of health and safety training.

The results presented here can be viewed as limited in the sense that all obtained data are based on self-report by trainees. It was infeasible to conduct interviews with representatives of plant management and local union leadership at the many different facilities represented by these trainees to compare perceptions of those of the trainees. It should be noted, however, that a number of these trainees were elected local union officials or senior supervisory personnel. Also, there was no evaluation of observed data nor were written records of training impact such as illness and accident records reviewed. Such data are difficult and expensive to collect. Interpretation is even more problematic since there are multiple other factors which can have effects besides the training itself. Moreover, collecting these data in a multi-plant program without prior management approval is not feasible. Even lacking these types of data, the combination of the quantitative and qualitative data presented here is mutually reinforcing and convincing.

\section{CONCLUSION}

The positive results reported here and in other NIEHSfunded training programs provide compelling arguments for continued funding of such training efforts provided to workers in industrial plants where they may need to respond to chemical releases. As Weidner states, "self-reported data and personal anecdotes from the workplace are extremely compelling and should be of value in any debate over continued support for training efforts" [Weidner et al., 1998]. There is now ample impact evaluation literature that demonstrates the positive direct effects this training has had on workers and their workplaces. The trainees have seen this actualized and when asked if there was anything else they would like to say about the training, most said they would like to attend more training of a similar design. One trainee summed up how most others responded, "I hope they keep these kinds of programs going. I think they are well needed."

\section{REFERENCES}

Kaufman, JS. 1996. Evaluating employee involvement programs: a case study of a union-based worker-trainer program in health and safety. A dissertation submitted in partial fulfillment of the requirements for the degree of Doctor of Philosophy (Psychology), University of Michigan.

Kurtz JR, Robins TG, Schork MA. 1997. An evaluation of peer and professional trainers in a union-based occupational health and safety training program. J Occ Env Med 39:661-671.

Luskin J, Somers C, Wooding J, Levenstein C. 1992. Teaching health and safety: problems and possibilities for learner-centered training. Am J Ind Med 22:665-676.

McQuiston TH, Coleman P, Walerstein N, Marcus AC, Morawetz JS, Ortlieb DW. 1994. Hazardous waste worker education long term effects. J Occ Med 36:1310-1323.

Merrill, M. 1994. Trust in training: the Oil, Chemical, and Atomic Workers International Union worker-to-worker training program. Occ Med: State of the Arts Revs 9:341-354.

Weidner BL, Grotsch AR, Delnevo CD, Newman JB, McDonald M. 1998. Worker health and safety training: assessing impact among responders. Am J Ind Med 33:241-246. 